\title{
Studi Estimasi Emisi Gas Rumah Kaca Pada Pengelolaan Sampah Di TPA Gunung Kupang Banjarbaru Kalimantan Selatan
}

\author{
Firdaus Oktafayanza' ${ }^{1}$, Rizqi Puteri Mahyudin'², Muhammad Firmansyah ${ }^{3}$ \\ 1,2,3Program Studi Teknik Lingkungan, Fakultas Teknik, ULM \\ JI. A. Yani Km 36, Banjarbaru, Kalimantan Selatan, 70714 , Indonesia \\ *surel: rizqiputeri@ulm.ac..id
}

\begin{abstract}
This study aims to identify the generation, composition and management of waste in the form of waste transportation, heavy equipment operations, processing waste at the Gunung Kupang Landfill, estimating greenhouse gas (GHG) emissions in the current waste management conditions. Waste generation was obtained from recording incoming waste at weigh stations and the composition of waste based on IPCC obtained from measurements of 8 days as many as $1 \mathrm{~m} 3$. GHG emissions in waste management in Landfill use the IPCC calculation method and recycling activities assisted by Waste Reduction Model (WARM). The amount of waste entering the Gunung Kupang Landfill is 39.491 Tons/year. The most waste composition is food waste, which is $49,42 \%$. Estimates of GHG emissions from the present condition of waste management at the Gunung Kupang Landfill amounted to $1.061 .116,93 \mathrm{TCO} 2 \mathrm{E} /$ year of emissions resulting from the amount of waste entering 39.491 Tons/year, composting leftover food waste 56,66 tons/year, recycling as much plastic waste 62,20 Tons/year, 39.371 Tons/year of unprocessed or dumped waste and the use of diesel fuel for transporting waste and heavy equipment operations as much as 391.645 Liters/year.
\end{abstract}

Keywords:

GHG emissions,

Landfill,

Waste management

Submitted: June 2021

Reviewed: August 2021

Published: August 2021

\section{INTISARI}

Studi ini bertujuan untuk mengidentifikasi timbulan, komposisi dan pengelolaan sampah berupa pengangkutan sampah, operasional alat berat, pengolahan sampah di TPA Gunung Kupang, mengestimasi emisi gas rumah kaca (GRK) pada kondisi pengelolaan sampah sekarang. Timbulan sampah didapatkan dari pencatatan sampah masuk di jembatan timbang dan komposisi sampah berdasarkan IPCC didapatkan dari pengukuran sampel 8 hari sebanyak $1 \mathrm{~m} 3$. Emisi GRK pada pengelolaan sampah di TPA menggunakan metode perhitungan IPCC dan kegiatan daur ulang dibantu Waste Reduction Model (WARM). Timbulan sampah yang masuk ke TPA Gunung Kupang adalah 39.491 Ton/tahun. Komposisi sampah terbanyak adalah sampah sisa makanan yaitu 49,42\%. Perkiraan emisi GRK dari kondisi sekarang pengelolaan sampah di TPA Gunung Kupang sebesar 1.061.116,93 TCO2E/tahun emisi tersebut dihasilkan dari jumlah sampah yang masuk 39.491 ton/tahun, pengomposan sampah sisa makanan 56,66 Ton/tahun, daur ulang sampah plastik sebanyak 62,20 Ton/tahun, sampah tidak diolah atau ditimbun sebanyak 39.371 Ton/tahun dan penggunaan bahan bakar minyak diesel untuk pengangkutan sampah dan operasional alat berat sebanyak 391.645 Liter/tahun.

\author{
Kata Kunci: \\ Emisi GRK, \\ Pengelolaan sampah, \\ Tempat Pemrosesan Akhir
}

Diterima: Juni 2021

Direview: Agustus 2021

Dipublikasi: Agustus 2021 


\section{PENDAHULUAN}

Jumlah sampah yang meningkat mengakibatkan pengelolaan sampah semakin rumit karena banyak teknologi dan pengetahuan yang digunakan untuk mengelola sampah agar mempunyai nilai jual, dapat digunakan kembali sehingga tidak mencemari lingkungan [6]. Permasalahan sampah menjadi perhatian yang cukup serius, karena berdampak terhadap perubahan iklim yang mengakibatkan pemanasan global [3]. Pemanasan global disebabkan meningkatnya suhu udara di atmosfer karena emisi dari beberapa gas rumah kaca meningkat seperti $\mathrm{CO}_{2}, \mathrm{CH}_{4}$ dan $\mathrm{N}_{2} \mathrm{O}$ [2].

Pengelolaan sampah menghasilkan emisi gas rumah kaca seperti proses pembakaran bahan bakar mesin dari fosil yang digunakan untuk kegiatan pengangkutan sampah dari tempat penampungan sementara (TPS) ke Tempat Pemrosesan Akhir (TPA) emisi yang di hasilkan berupa $\mathrm{CO}_{2}, \mathrm{CH}_{4}$ dan $\mathrm{N}_{2} \mathrm{O}$, proses pengolahan sampah secara biologi juga menghasilkan emisi seperti penimbunan sampah di TPA dimana sampah organik terdegradasi menghasilkan $\mathrm{CH}_{4}$ [5]. Emisi gas metan yang dihasilkan dari sampah yang ditimbun di TPA diperkirakan 3-19 persen sumber antropogenik (pencemaran tidak alami karena disebabkan aktivitas manusia) di dunia. Emisi $\mathrm{CH}_{4}$ berpotensi pemanasan 21 kali dari $\mathrm{CO}_{2}[9]$.

Pada tahun 2017 berdasarkan data dari Dinas Lingkungan Hidup Kota Banjarbaru yang masuk ke TPA Gunung Kupang sebesar 108 ton/hari. Luas lahan TPA Gunung Kupang pada tahun 2005 adalah $10 \mathrm{Ha}$ dengan luas lahan yang sudah terpakai untuk penimbunan sampah adalah 8 Ha pada tahun 2018. TPA Gunung Kupang beberapa tahun kedepan akan menampung lebih banyak sampah seiring pertambahan penduduk Jumlah penduduk Kota Banjarbaru yang meningkat berbanding lurus dengan peningkatan jumlah timbulan sampah yang harus dikelola [8].

Produksi gas rumah kaca berkaitan dengan fraksi organik biodegradable yang ditimbun TPA mengalami dekomposisi dan menghasilkan emisi gas metana $\left(\mathrm{CH}_{4}\right)$ dan karbondioksida $\left(\mathrm{CO}_{2}\right)$ [1]. Emisi dari kegiatan pengangkutan menggunakan kendaraan dari garasi kemudian ke TPS dilanjutkan ke TPA dan proses pengolahan sampah perkotaan juga berkontribusi emisi gas rumah kaca karena menghasilkan karbon dioksida $\left(\mathrm{CO}_{2}\right)$, metan $\left(\mathrm{CH}_{4}\right)$ dan $\mathrm{N}_{2} \mathrm{O}$ [7].

Berdasarkan target penurunan emisi gas rumah kaca pada tahun 2011 telah dikeluarkan Peraturan Presiden No. 61 tentang rencana aksi nasional penurunan emisi gas rumah kaca dan Peraturan Presiden No. 71 tentang penyelenggaran inventerisasi gas rumah kaca nasional tujuan dari penelitian ini adalah untuk menghitung emisi gas rumah kaca pada pengelolaan sampah di TPA Gunung Kupang Banjarbaru dari kegiatan pengangkutan sampai kegiatan pengolahan sampah di TPA tersebut menggunakan metode pendekatan intergovernmental Panel on Climate Change (IPCC) sehingga dapat mengestimasikan emisi gas rumah kaca sektor 
persampahan dari pengelolaan sampah di TPA Gunung Kupang Banjarbaru.

Penelitian ini bertujuan untuk mengidentifikasi timbulan, komposisi dan pengelolaan sampah berupa pengangkutan, operasional alat berat dan pengolahan sampah di TPA Gunung Kupang, mengestimasi emisi gas rumah kaca pada pengelolaan sampah di TPA Gunung Kupang. Manfaat dari penelitian ini diharapkan dapat dijadikan informasi potensi dan mengestimasikan emisi gas rumah kaca yang dihasilkan dari pengelolaan sampah di TPA Gunung Kupang Banjarbaru bagi instansi terkait.

\section{METODOLOGI}

\section{Rancangan Penelitian}

Penelitian ini dilakukan di TPA Gunung Kupang, Kelurahan Cempaka, Kota Banjarbaru. Data yang diperlukan untuk estimasi gas rumah kaca dari pengelolaan sampah di TPA Gunung Kupang berupa data sekunder dan data primer. Data sekunder berupa data pengelolaan sampah di TPA Gunung Kupang yaitu penggunaan bahan bakar untuk pengangkutan sampah dan pengoperasian alat berat, data jumlah sampah yang masuk, data pengolahan sampah dan data default IPCC sektor persampahan. Data primer didapatkan dari pengukuran langsung di TPA berupa data komposisi sampah yang masuk ke TPA selama 8 hari sebanyak $1 \mathrm{~m}^{3}$. Jenis komposisi sampah disesuaikan dengan komposisi dari IPCC.

Estimasi GRK di TPA Gunung Kupang menggunakan rumus atau metode dari
Intergovernmental Panel on Climate Change (IPCC) untuk menghitung GRK dari kegiatan pengangkutan sampah, pengoperasian alat berat, pembuangan sampah di TPA dan pengolahan sampah secara biologi atau pengomposan. Selain menggunakan perhitungan dari IPCC, perhitungan dari Waste Reduction Model (WARM) untuk membantu dalam perhitungan emisi GRK dari kegiatan pengurangan sampah dari pemulung.

\section{Teknik Pengumpulan Data}

Pengumpulan data primer dan sekunder pada penelitian ini dapat dilihat pada rangkuman Tabel 1.

Tabel 1. Teknik Pengumpulan Data

\begin{tabular}{|c|c|c|c|}
\hline No & Data & Sumber & Satuan \\
\hline \multicolumn{4}{|c|}{ Data Primer } \\
\hline 1 & $\begin{array}{l}\text { Timbulan } \\
\text { sampah di } \\
\text { TPA Gunung } \\
\text { Kupang }\end{array}$ & $\begin{array}{l}\text { Jembatan } \\
\text { timbang di TPA } \\
\text { Gunung Kupang }\end{array}$ & Ton/tahun \\
\hline 2 & $\begin{array}{l}\text { Komposisi } \\
\text { sampah di TPA } \\
\text { Gunung } \\
\text { Kupang } \\
\text { berdasar IPCC } \\
\text { GL } 2006 \\
\text { volume } 5 \\
\end{array}$ & $\begin{array}{l}\text { Pengambilan } \\
\text { sampel dengan } \\
\text { Metode SNI 19- } \\
3964-1994\end{array}$ & $\begin{array}{c}\text { Kg, } \\
\% / j e n i s \\
\text { sampah }\end{array}$ \\
\hline \multicolumn{4}{|c|}{ Data Sekunder } \\
\hline 3 & $\begin{array}{l}\text { Profil TPA, } \\
\text { melingkupi } \\
\text { karakter fisik } \\
\text { TPA (luas dan } \\
\text { kedalaman } \\
\text { urugan); sistem } \\
\text { pengoperasian } \\
\text { (jenis landfill) }\end{array}$ & $\begin{array}{l}\text { TPA Gunung } \\
\text { Kupang } \\
\text { Banjarbaru }\end{array}$ & - \\
\hline 4 & $\begin{array}{l}\text { BBM, dari } \\
\text { pemakaian } \\
\text { kendaraan } \\
\text { pengangkut } \\
\text { dan alat berat }\end{array}$ & $\begin{array}{l}\text { Dinas } \\
\text { Lingkungan } \\
\text { Hidup } \\
\text { Banjarbaru, } \\
\text { bidang } \\
\text { pengaturan dan } \\
\text { pengendalian } \\
\text { persampahan }\end{array}$ & $\begin{array}{l}\text { Liter, Ton } \\
\text { Joule }\end{array}$ \\
\hline 5 & $\begin{array}{l}\text { Aktivitas } \\
\text { pengelolaan, } \\
\text { mencakup: } \\
\text {-kegiatan } \\
\text { pemulungan } \\
\text { sampah } \\
\text {-komposting }\end{array}$ & $\begin{array}{l}\text { Inventarisasi TPA } \\
\text { Gunung Kupang } \\
\text { Banjarbaru }\end{array}$ & $\begin{array}{l}\text { Kg (untuk } \\
\text { sampah } \\
\text { yang } \\
\text { diolah) }\end{array}$ \\
\hline
\end{tabular}




\begin{tabular}{lllc}
\hline No & \multicolumn{1}{c}{ Data } & Sumber & Satuan \\
\hline & Nilai default & & \\
& untuk \\
& Indonesia (Asia & & \\
6 & IPCC GL 2006 & - \\
& Tenggara): & & \\
& DOC, MCF, & & \\
& OF, NCVs & \\
\hline
\end{tabular}

\section{Prosedur Penelitian}

Prosedur studi estimasi GRK dari pengelolaan TPA Gunung Kupang dilakukan perhitungan setelah data primer dan data sekunder telah didapatkan. Perhitungan emisi yang dihasilkan dari data bahan bakar yang digunakan pengangkutan truk sampah dan penggunaan alat berat dengan rumus yaitu:

Emisi $=\sum a($ Fuel $a \cdot E F a)$

Keterangan:

Emisi = Jumlah emisi yang dihasilkan $(\mathrm{Kg})$

Fuel $a=$ Jumlah konsumsi BBM (TJ/Tahun)

$\mathrm{EFa} \quad=$ Faktor Emisi $(\mathrm{Kg} / \mathrm{Ti})$

Jumlah Konsumsi BBM dalam satuan $\mathrm{Ti} /$ Tahun dapat diketahui dengan cara menghitung konsumsi energi yaitu jumlah penggunaan BBM (liter) dikalikan nilai kalor BBM untuk nilai minyak solar di Indonesia yaitu 0,000036 $\mathrm{Ti} /$ liter sehingga didapatkan fuel a.

Perhitungan emisi GRK dari kegiatan pengolahan secara biologi di TPA menggunakan data jumlah sampah organik yang diolah selama satu tahun dan jenis pengolahan sampah secara biologi. Perhitungan emisi GRK dari kegiatan pengolahan secara biologi di TPA menggunakan metode IPCC yaitu:

Emisi $\mathrm{CH}_{4}=(\mathrm{Mi} \times \mathrm{EFi}) \times 10^{-3}-\mathrm{R}$

Keterangan:

$\mathrm{Mi}=$ Berat sampah, $\mathrm{Gg}$
$\mathrm{EFi} \quad=$ Faktor emisi, $\mathrm{G} \mathrm{CH}_{4} / \mathrm{Kg}$

$\mathrm{R}=$ Jumlah gas $\mathrm{CH}_{4}$ yang dikelola per tahun, $\mathrm{Gg} \mathrm{CH} 4$

$\mathrm{i}=$ Jenis pengolahan secara biologi

Perhitungan pengurangan emisi GRK dari kegiatan pemilahan sampah plastik yang dapat digunakan kembali di TPA, dibantu menggunakan metode Waste Reduction Model (Warm) dengan cara memasukkan data jumlah sampah yang masuk ke TPA (Ton/tahun), jumlah sampah plastik yang dipilah oleh pemulung (Ton/tahun) dan jumlah sampah yang tidak dipilah oleh pemulung (Ton/tahun).

Perhitungan emisi GRK dari sampah yang tidak diolah di TPA Gunung kupang sisa dari sampah yang tidak diolah dari pengomposan dan daur ulang dapat dihitung menggunakan data jumlah sampah di TPA, komposisi sampah, dan data default serta metode perhitungan dari IPCC. Perhitungan emisi GRK dari sampah yang tidak diolah dengan rumus yaitu:

$\mathrm{CH}_{4}=\mathrm{MSW}_{T} \times \mathrm{MSW}_{F} \times M C F \times D O C \times \mathrm{DOC}_{F} \times F \times \frac{16}{12}-$

$R \times 1-O X$

Keterangan:

MSWT = Jumlah sampah di TPA (Gg/Tahun)

MSWF = Persentase sampah masuk ke TPA, $80 \%$

MCF = Faktor koreksi metana 0,8

DOC = Degradasi Organic Carbon, nilai default IPCC

DOCF = Nilai default DOCF untuk Indonesia adalah 0,5

$\mathrm{F} \quad=$ Nilai default 0,5 untuk fraksi gas metana di TPA

$\mathrm{R}=0$ karena Indonesia belum memiliki alat pengolahan $\mathrm{CH} 4$

OX = Nilai default 0,1 faktor oksidasi

Berdasarkan hasil dari perhitungan emisi GRK dari penggunaan $B B M$ pengangkutan 
sampah dan operasional alat berat, pengolahan sampah yang diolah dan tidak diolah di TPA Gunung Kupang dijumlahkan, sehingga didapatkan total emisi GRK yang dihasilkan dari pengelolaan sampah di TPA Gunung Kupang dengan kondisi sekarang.

\section{HASIL DAN PEMBAHASAN}

\section{Kondisi Saat Ini Pengelolaan Sampah di TPA}

\section{Gunung Kupang Kota Banjarbaru}

Berdasarkan data Dinas Lingkungan Hidup Kota Banjarbaru bidang pengaturan dan pengendalian persampahan, kegiatan pengangkutan sampah menggunakan truk di Kota Banjarbaru menggunakan 355.145 liter/tahun. Berdasarkan wawancara dengan pengelola TPA, TPA menggunakan 2 buah alat berat untuk mengelola sampah di TPA yaitu excavator dan loader memerlukan bahan bakar minyak diesel sebanyak 36.500 liter/tahun. Penggunaan bahan bakar menghasilkan emisi gas rumah kaca yaitu $\mathrm{CO}_{2}$, selain menghasilkan $\mathrm{CO}_{2}$ menurut IPCC GL 2006 juga menghasilkan $\mathrm{CH}_{4}$ dan $\mathrm{N}_{2} \mathrm{O}$ [4].

Timbulan sampah yang masuk ke TPA Gunung Kupang pada tahun 2017 berdasarkan hasil pencatatan di jembatan timbang sebesar 39.491 ton/tahun atau 108 ton/hari. Hasil pengukuran komposisi sampah selama 8 di TPA Gunung Kupang berdasarkan IPCC GL 2006 dapat dilihat pada Tabel 2.

Tabel 2. Komposisi Sampah TPA Gunung Kupang Tahun 2018

\begin{tabular}{lc}
\hline Komposisi & $\begin{array}{c}\text { Rata-Rata } \\
(\%)\end{array}$ \\
\hline Sisa Makanan & 49,42 \\
Kertas & 10,45
\end{tabular}

\begin{tabular}{lc}
\hline \multicolumn{1}{c}{ Komposisi } & $\begin{array}{c}\text { Rata-Rata } \\
(\%)\end{array}$ \\
\hline Popok & 2,39 \\
Kayu & 2,62 \\
Taman dan Kebun & 11,65 \\
Tekstil & 2,35 \\
Karet dan Kulit & 1,98 \\
Logam & 0,66 \\
Kaca & 1,72 \\
Plastik & 15,84 \\
Sampah Lainnya & 0,93 \\
\hline Total & 100 \\
\hline
\end{tabular}

Pada Tabel 2. komposisi sampah berdasarkan kemampuan untuk hancur atau terurai di kelompokkan menjadi 2 yaitu sampah mudah terurai dan sampah tidak mudah terurai dapat dilihat pada Gambar 1 dan 2.

Pada Gambar 1 komposisi sampah mudah terurai terbanyak adalah sampah sisa makanan sebanyak 49,42\%. Tingginya komposisi sampah sisa makanan disebabkan karena banyaknya jumlah masyarakat mengonsumsi makanan setiap harinya [11]. Pada Gambar 2 komposisi sampah tidak mudah terurai terbanyak adalah sampah plastik sebanyak 15,84\%. Banyaknya penggunaan plastik digunakan untuk membungkus kemasan makanan, minuman dan membungkus sampah lain seperti sampah sisa makanan untuk dibuang.

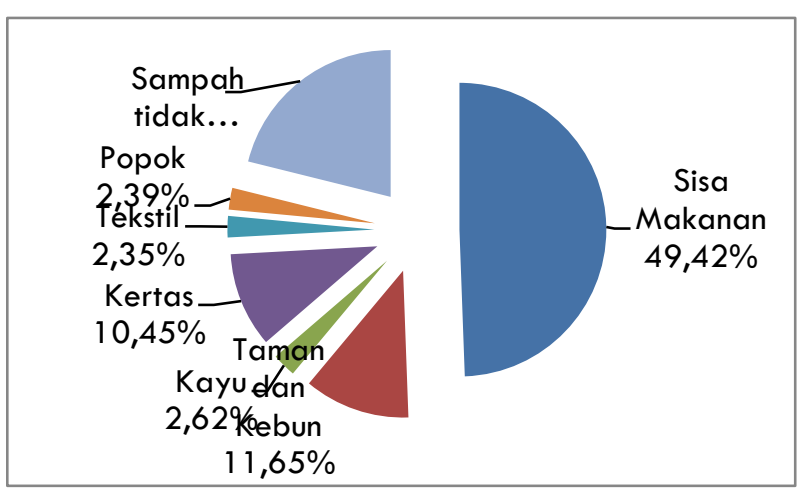


Gambar 1. Komposisi Sampah Mudah Terurai di TPA Gunung Kupang

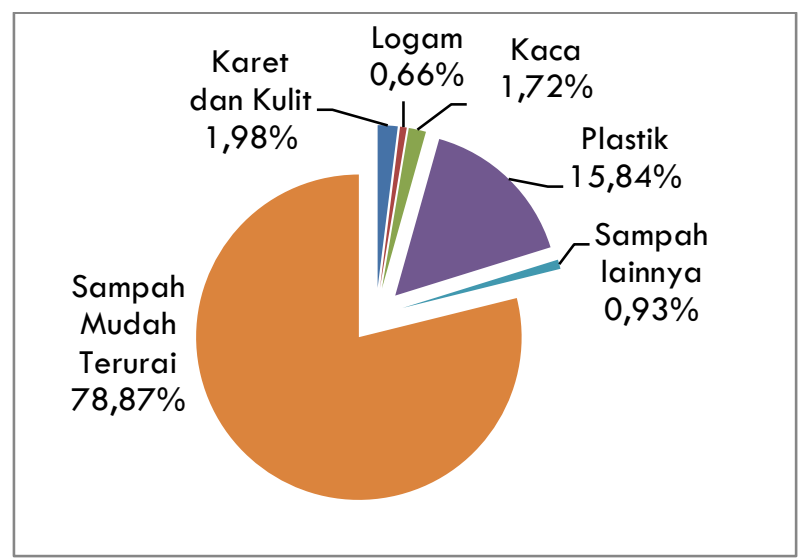

Gambar 2. Komposisi Sampah Tidak Mudah Terurai di TPA Gunung Kupang

Pengolahan sampah di TPA Gunung kupang bertujuan untuk mengurangi jumlah sampah yang ditimbun. Kegiatan pengolahan sampah di TPA yaitu pengomposan dan daur ulang sampah plastik. Jumlah pengolahan sampah di TPA dapat dilihat pada Tabel 3.

\begin{tabular}{ccccccc}
\hline $\begin{array}{c}\text { ah } \\
\text { masuk } \\
(\mathrm{Kg} / \mathrm{T} \\
\text { ahun) }\end{array}$ & $\begin{array}{c}\text { Comp } \\
\text { ostin }\end{array}$ & $\begin{array}{c}\text { Daur } \\
\text { Ulan } \\
\mathrm{g}\end{array}$ & $\begin{array}{c}\text { ah } \\
(\mathrm{Kg} / \mathrm{T} \\
\text { ahun) }\end{array}$ & $\begin{array}{c}\text { Comp } \\
\text { ostin } \\
\mathrm{g}\end{array}$ & $\begin{array}{c}\text { Daur } \\
\text { Ulan } \\
\mathrm{g}\end{array}$ & $\begin{array}{c}\text { Samp } \\
\mathrm{ah} \\
(\%)\end{array}$ \\
\hline 39.49 & $\begin{array}{c}56.6 \\
0.629\end{array}$ & $\begin{array}{c}62.2 \\
0\end{array}$ & $\begin{array}{c}39.37 \\
1.774\end{array}$ & 0,14 & 0,16 & 99,7 \\
\hline
\end{tabular}

Kegiatan pengolahan kompos dari sampah sisa makanan akan menghasilkan emisi GRK tetapi jumlah emisi yang dihasilkan akan lebih sedikit daripada tidak diolah [4]. Sampah organik seperti sisa makanan yang tidak diolah akan terurai didalam tanah dan menghasilkan emisi GRK berupa $\mathrm{CH}_{4}$. Kegiatan daur ulang juga akan menghasilkan emisi GRK tetapi jumlah emisi yang dihasilkan akan lebih sedikit daripada tidak olah, karena akan mengurangi penggunaan bahan dan penggunaan energi bahan bakar fosil untuk membuat bahan tersebut [10].

\section{Estimasi Emisi GRK pada Pengelolaan Sampah di TPA Gunung Kupang \\ Perkiraan emisi GRK dari penggunaan bahan bakar minyak diesel pengangkutan sampah dan operasional alat berat di TPA menggunakan rumus (1) sehingga hasil perhitungan emisi GRK dari penggunaan bahan bakar dapat dilihat pada Tabel 4 .}

Tabel 3. Pengolahan Sampah di TPA Gunung

Kupang

\begin{tabular}{ccccc}
\hline Jumla & Sampah & Penim & Sampah & Penim \\
$\mathrm{h}$ & diolah & bunan & diolah & buna \\
Samp & $(\mathrm{Kg} /$ Tahun $)$ & Samp & $(\%)$ & $\mathrm{n}$ \\
\hline
\end{tabular}

Tabel 4. Emisi GRK dari Penggunaan BBM pada Pengelolaan Sampah di TPA

\begin{tabular}{|c|c|c|c|c|c|c|c|}
\hline Sumber & $\begin{array}{l}\text { Konsumsi } \\
\text { BBM } \\
\text { (L/tahun) }\end{array}$ & $\begin{array}{l}\text { Nilai Kalor } \\
\text { Solar }(\mathrm{Ti} / \mathrm{L})\end{array}$ & $\begin{array}{l}\text { Konsumsi } \\
\text { Energi } \\
\text { (Ti/tahun) }\end{array}$ & $\begin{array}{c}\text { Emisi } \mathrm{CO}_{2} \\
\left(\mathrm{TCO}_{2} \mathrm{E}\right)\end{array}$ & $\begin{array}{c}\text { Emisi } \mathrm{CH}_{4} \\
\left(\mathrm{TCO}_{2} \mathrm{E}\right)\end{array}$ & $\begin{array}{l}\text { Emisi } \mathrm{N}_{2} \mathrm{O} \\
\left(\mathrm{TCO}_{2} \mathrm{E}\right)\end{array}$ & $\begin{array}{c}\text { Total } \\
\left(\mathrm{TCO}_{2} \mathrm{E}\right)\end{array}$ \\
\hline Pengangkutan & 355.145 & 0,000036 & 12,79 & 947,38 & 1,05 & 14,86 & 963,29 \\
\hline
\end{tabular}




\begin{tabular}{|c|c|c|c|c|c|c|c|}
\hline $\begin{array}{l}\text { Operasional } \\
\text { alat berat }\end{array}$ & 36.500 & 0,000036 & 1,31 & 97,37 & 0,11 & 1,53 & 99 \\
\hline & & & & & & & $1.062,29$ \\
\hline
\end{tabular}

Perkiraan emisi GRK dari pengolahan sampah secara biologi yaitu pengomposan sampah sisa makananan menggunakan rumus (2), sehingga hasil perhitungan emisi GRK dari pengomposan dapat dilihat pada Tabel 5.

Tabel 5. Emisi GRK dari Pengomposan Sampah di TPA

\begin{tabular}{|c|c|c|c|c|c|c|c|c|}
\hline \multirow[t]{2}{*}{$\begin{array}{c}\text { Sistem } \\
\text { Pengolahan } \\
\text { Biologi }\end{array}$} & \multirow[t]{2}{*}{$\begin{array}{l}\text { Kategori } \\
\text { Sampah }\end{array}$} & \multirow{2}{*}{$\begin{array}{c}\text { Total } \\
\text { Composting } \\
\text { (Gg/Tahun) } \\
\text { a }\end{array}$} & \multirow{2}{*}{$\begin{array}{l}\text { Faktor } \\
\text { Emisi }(\mathrm{g} \\
\left.\mathrm{CH}_{4} / \mathrm{Kg}\right) \\
\text { b }\end{array}$} & \multirow{2}{*}{$\begin{array}{c}\text { Emisi } \mathrm{CH}_{4} \\
\text { Kotor }(\mathrm{Gg} \\
\left.\mathrm{CH}_{4}\right) \\
\mathrm{c}=\left(\begin{array}{l}\mathrm{a} \times \mathrm{b} \\
\times 10^{-3}\end{array}\right. \\
\times 1\end{array}$} & \multirow{2}{*}{$\begin{array}{c}\text { Metan } \\
\text { yang } \\
\text { dioalah } \\
\text { per tahun } \\
\left(\mathrm{Gg} \mathrm{CH}_{4}\right) \\
\text { d }\end{array}$} & \multirow{2}{*}{$\begin{array}{l}\text { Emisi } \mathrm{CH}_{4} \\
\text { murni }(\mathrm{Gg} \\
\left.\quad \mathrm{CH}_{4}\right) \\
\mathrm{e}=(\mathrm{c}-\mathrm{d})\end{array}$} & \multirow{2}{*}{$\begin{array}{c}\text { Emisi } \\
\mathrm{CH}_{4} \\
\text { murni } \\
(\text { Ton } \\
\mathrm{CH}_{4} \text { ) } \\
\mathrm{f}=\mathrm{ex} \\
1000 \\
\end{array}$} & \multirow{2}{*}{$\begin{array}{c}\text { Emisi CH} \mathrm{CH}_{4} \\
\text { murni } \\
\left(\mathrm{TCO}_{2} \mathrm{E}\right) \\
\mathrm{g}=\mathrm{fx} \\
21 \\
\end{array}$} \\
\hline & & & & & & & & \\
\hline Kompos & $\begin{array}{c}\text { Sisa } \\
\text { makanan }\end{array}$ & 0,056655 & 4 & 0,000227 & 0 & 0,000227 & 0,23 & 4,76 \\
\hline
\end{tabular}

Perkiraan emisi GRK yang dihasilkan dari pengolahan daur ulang sampah di TPA dibantu menggunakan perhitungan dari Waste Reduction Model (WARM), sehingga hasil perhitungan emisi GRK dari pengolahan daur ulang sampah dapat dilihat pada Tabel 6.

Tabel 6. Emisi GRK dari Daur Ulang Sampah di TPA

\begin{tabular}{cccccc}
\hline $\begin{array}{c}\text { Jenis } \\
\text { Sampah }\end{array}$ & $\begin{array}{c}\text { Jumlah Sampah } \\
\text { Masuk Ke TPA } \\
\text { (Ton/Tahun) }\end{array}$ & $\begin{array}{c}\text { Pemilahan Plastik } \\
\text { Daur Ulang } \\
\text { (Ton/Tahun) }\end{array}$ & $\begin{array}{c}\text { Total sampah } \\
\text { tidak terpilah } \\
\text { (Ton/Tahun) }\end{array}$ & $\begin{array}{c}\text { Total emisi GRK } \\
\text { tanpa Pemilahan } \\
\text { (TCO }{ }_{2} \text { E) }\end{array}$ & $\begin{array}{c}\text { Total Emisi GRK } \\
\text { dengan kegiatan } \\
\text { pemilahan }\left(\mathrm{TCO}_{2} \mathrm{E}\right)\end{array}$ \\
\hline Plastik & 39.491 & 62,2 & 39.429 & 126,7 & 61,82 \\
\hline
\end{tabular}

Perkiraan emisi GRK yang dihasilkan dari sampah yang tidak diolah atau ditimbun di TPA menggunakan rumus (3),sehingga hasil perhitungan emisi GRK dari sampah yang tidak diolah dapat dilihat pada Tabel 7.

Tabel 7. Emisi GRK dari Sampah yang Tidak Diolah di TPA

\begin{tabular}{|c|c|c|c|c|c|c|c|c|}
\hline Komposisi & $\begin{array}{l}\text { Jumlah } \\
\text { sampah } \\
\text { yang } \\
\text { tidak } \\
\text { diolah di } \\
\text { TPA } \\
\text { (Gg/tahu } \\
\text { n) }\end{array}$ & $\begin{array}{l}\text { Komposisi } \\
\text { sampah } \\
\text { di TPA } \\
(\%)\end{array}$ & $\begin{array}{c}\text { Komposisi } \\
\text { sampah di } \\
\text { TPA } \\
\text { (Gg/Tahu } \\
\text { n) }\end{array}$ & $\begin{array}{c}\text { DOCi } \\
\text { default } \\
\text { IPCC } \\
(\%)\end{array}$ & $\begin{array}{c}\text { DOC } \\
\text { (Gg } \\
\text { C/Gg } \\
\text { Sampah) }\end{array}$ & $\begin{array}{c}\mathrm{CH}_{4} \\
(\mathrm{Gg} / \text { tahun })\end{array}$ & $\begin{array}{c}\mathrm{CH}_{4} \\
\text { (Ton/tahun) }\end{array}$ & $\begin{array}{c}\mathrm{CH}_{4} \\
\left(\mathrm{TCO}_{2} \mathrm{E}\right)\end{array}$ \\
\hline A & $b$ & c & $d=b \times c$ & e & $\begin{array}{c}f=e x \\
d\end{array}$ & 9 & $h=g \times 1000$ & $I=h \times 21$ \\
\hline $\begin{array}{c}\text { Sisa } \\
\text { Makanan }\end{array}$ & & 49,42 & 19,46 & 15 & 2,92 & 22,06 & $22.063,03$ & $\begin{array}{c}463.323,6 \\
7\end{array}$ \\
\hline Kertas & 39,37 & 10,45 & 4,11 & 40 & 1,65 & 12,44 & $12.440,78$ & $\begin{array}{c}261.256,3 \\
0\end{array}$ \\
\hline Popok & & 2,39 & 0,94 & 24 & 0,23 & 1,71 & $1.707,18$ & $35.850,86$ \\
\hline Kayu & & 2,62 & 1,03 & 43 & 0,44 & 3,35 & $3.353,06$ & $70.414,20$ \\
\hline
\end{tabular}




\begin{tabular}{|c|c|c|c|c|c|c|c|}
\hline $\begin{array}{l}\text { Taman } \\
\text { dan } \\
\text { Kebun }\end{array}$ & 11,65 & 4,59 & 20 & 0,92 & 6,93 & $6.934,69$ & $\begin{array}{c}145.628,5 \\
1\end{array}$ \\
\hline Tekstil & 2,35 & 0,93 & 24 & 0,22 & 1,68 & $1.678,61$ & $35.250,85$ \\
\hline $\begin{array}{c}\text { Karet } \\
\text { dan Kulit }\end{array}$ & 1,98 & 0,78 & 39 & 0,30 & 2,30 & $2.298,27$ & $48.263,66$ \\
\hline & Total & & & 6,68 & 50,48 & $50.475,62$ & $\begin{array}{c}1.059 .988 \\
06\end{array}$ \\
\hline
\end{tabular}

Total emisi GRK yang dihasilkan dari pengelolaan sampah di TPA Gunung Kupang dapat dilihat pada Tabel 8.

Tabel 8. Emisi GRK dari Pengelolaan Sampah di TPA Gunung Kupang

\begin{tabular}{|c|c|c|}
\hline \multicolumn{2}{|c|}{ Sumber Emisi } & $\begin{array}{c}\text { Emisi GRK } \\
\left(\mathrm{TCO}_{2} \mathrm{E}\right)\end{array}$ \\
\hline $\begin{array}{l}\text { Pengangkutan } \\
\text { Operasional Alat }\end{array}$ & $\begin{array}{l}\text { Sampah dan } \\
\text { Berat di TPA }\end{array}$ & $1.062,29$ \\
\hline $\begin{array}{l}\text { Pengomposan } \\
\text { Makanan }\end{array}$ & Sampah Sisa & 4,76 \\
\hline \multicolumn{2}{|c|}{ Daur Ulang Sampah Plastik } & 61,82 \\
\hline $\begin{array}{l}\text { Sampah Tidak } \\
\text { Ditimbun }\end{array}$ & Diolah & $1.059 .988,06$ \\
\hline \multicolumn{2}{|c|}{ Total } & $1.061 .116,93$ \\
\hline
\end{tabular}

Pengelolaan sampah di TPA Gunung Kupang menghasilkan emisi GRK yaitu dari penggunaan $B B M$ jenis minyak diesel sebesar $1.062,29 \mathrm{TCO}_{2} \mathrm{E} /$ tahun, pengolahan sampah sisa makanan berupa kompos sebesar 4,76 $\mathrm{TCO}_{2} \mathrm{E} /$ tahun, pengolahan sampah plastik berupa daur ulang sebesar 61,82 $\mathrm{TCO}_{2} \mathrm{E} /$ tahun dan sampah yang tidak terolah sebesar 1.059.988,06 $\mathrm{TCO}_{2} \mathrm{E} /$ tahun sehingga jumlah emisi GRK yang dihasilkan dari kondisi pengelolaan sampah sekarang sebesar $1.061 .116,93 \mathrm{TCO}_{2} \mathrm{E} /$ tahun.

\section{KESIMPULAN}

Jumlah sampah yang masuk ke TPA Gunung Kupang pada tahun 2017 adalah 39.491 ton/tahun atau 108 ton/hari, komposisi sampah yang terdapat di TPA Gunung
Kupang pada tahun 2018 terbanyak adalah sampah mudah terurai sisa makanan sebesar $49,42 \%$ dan sampah tidak mudah terurai berupa plastik sebesar 15,84\%. Kegiatan pengurangan sampah yang terdapat di TPA Gunung Kupang yaitu pengomposan sampah sisa makanan sebanyak 56,66 ton/tahun dan daur ulang sampah plastik sebanyak 62,20 ton/tahun, sehingga sisa jumlah sampah yang tidak terolah atau ditimbun sebanyak 39.371 ton/tahun. Penggunaan bahan bakar minyak diesel yang digunakan truk pengangkut sampah sebanyak 355.145 liter/tahun, excavator dan loader sebanyak 36.500 liter/tahun. Perkiraan emisi gas rumah kaca dari kondisi sekarang pengelolaan sampah di TPA Gunung Kupang sebesar 1.061.116,93 $\mathrm{TCO}_{2} \mathrm{E} /$ tahun.

\section{REFERENSI}

[1] Abadi, B. A. dan W. Herumurti. (2013). Perhitungan Emisi Karbon Pengolahan Sampah Kota Probolinggo. Jurnal Teknik Pomits, 2(1): $1-4$.

[2] Ardhitama, A, Siregar., Y. I, Nofrizal. (2017). Analisis Pengaruh Konsentrasi Gas Rumah Kaca Terhadap Kenaikan Suhu Udara di Kota Pekanbaru dan Kota Padang. Jurnal IImu Lingkungan, 11 (1), 35-43.

[3] Cinthiawati, R., S. S. Moersidik, dan N. Suwartha. (2013). Estimasi dan Proyeksi Emisi 
Gas Rumah Kaca dari Pengelolaan Sampah di Kota Tangerang dengan Pendekatan Metode IPCC. Universitas Indonesia Library, 1-20.

[4] Friedrich, E. dan Trois, C. (2013). GHG emission factors develoved for the collection, transport and landfilling of municipal waste in South African Municipalities. Waste Management.

[5] Gentil, E., Christensen, T. H., Aoustin, E. (2009). GHG Accounting and Waste Management. Waste Management and Research, 27, 696706.

[6] Mahyudin, R. P. (2014). Strategi Pengelolaan Sampah Berkelanjutan. Jurnal Ilmiah Bidang Pengelolaan Sumberdaya Alam dan Lingkungan, 10, 33-40.

[7] Maziya, F. B. (2017). Pengelolaan Sampah Kecamatan Genteng Kota Surabaya. Jukung Jurnal Teknik Lingkungan, 3(2): 1-9.

[8] Mizwar, A. (2012). Penentuan Lokasi Tempat Pengolahan Akhir (TPA) Sampah Kota Banjarbaru Menggunakan Sistem Informasi Geografis (SIG). Jurnal Ilmiah Bidang Pengelolaan Sumberdaya Alam dan Lingkungan, 8(1), 1-7.

[9] Singh S. K., Anunay G., Rohit G., Shivangi G., dan Vivul V. (2016). Greenhouse Gases Emissions from Landfills: A Case of NCT of Delhi, India. Journal of Climatology \& Weather Forecasting, 1-6.

[10] Sunarto, Hadi, S. P. dan Purwanto (2013). Pengolahan Sampah Di TPS Tlogomas Malang untuk Mereduksi Jejak Karbon. Prosiding Seminar Nasional Pengelolaan Sumberdaya Alam dan Lingkungan, hal. 107115.

[11] Zahra, F., T. P. Damanhuri. (2011). Kajian Komposisi, Karakteristik, dan Potensi Daur Ulang Sampah di TPA Cipayung Depok. Jurnal Teknik Lingkungan, 17(1), 59-69. 